\title{
The Fatal Consequences of a Priori in the Natural Sciences, to be Replaced by Facts
}

\author{
Guy Berthault ${ }^{1 *}$ \\ Graduate engineer from Ecole Polytechnique. Promotion 1945, Knight of the Legion of Honor and the National Order of Merit Maurice Allais Award
}

${ }^{*}$ Corresponding Author: Guy Berthault, Graduate engineer from Ecole Polytechnique. Promotion 1945, Knight of the Legion of Honor and the National Order of Merit Maurice Allais Award, France; E-mail: berthault.guy@orange.fr

Received: October 25, 2019; Accepted: November 11, 2019; Published: November 19, 2019

\section{The conception of the universe through the ages}

Let us first speak, in Astronomy, of the original conception of the Universe, based on appearances. Every man, sailing on the sea, far from the coast, in good weather, sees the sky horizontally, in all directions, and vertically. He speaks of "celestial vault," an apparent sphere on which, by clear night, moves, together with the stars "carried" by it. That was what was described by Aristotle in his "De Coelo". Four centuries later, the astronomer Claude Ptolémée, in his work "L'Almageste", reporting on measurements of the positions of known planets he had compiled, consecrated the philosophical theory of Aristotle as a scientific theory, which were taught in Christian universities in the Middle Ages. However, in the $3^{\text {rd }}$ century BC, Aristarchus of Samos, adopting also the existence of the sphere of the fixed stars, postulated that the sun was the center. There were then, in the time of Ancient Greece and Rome, two philosophical schools, which agreed on the existence of this sphere carrying the fixed stars, but opposed on which star was at the center, either the Earth or the sun. This quarrel would re-emerge in the midst of Christianity in the Middle Ages. Copernicus, canon and astronomer, wondering about the irregular orbits described by the planets around the Earth, completed the calculations of the positions of the planets of Ptolemy and "demonstrated" that they revolved around the sun; he, however, attributed to them, by his approximate calculations of their distance from the sun, circular orbits which Kepler soon showed to be ellipses whose sun was a focus. Copernicus reported his theory in the work "De Revolutionibus Orbium Caelestium", published in 1543, which was sent after his death, by his friend Osiander, to Pope Paul III.

In his Preface, Copernicus, applying to the Earth the status of a planet, affirmed without proving that it revolved around the sun, and that, therefore, it was the sun that was the center of the world, quoting Trismegistus. who called the sun "visible god". Pope Paul III and his successors did not react. Tycho Brahé, astronomer of the king of Denmark, made at this time many measurements of the position and distance of the planets in the solar system, that Kepler would use and supplement by the particular study of Mars, which would lead him to formulate his three Laws in "Astronomia Nova" and "Harmonices Mundi". Tycho Brahé had just remarked that the apparent position of the sun and the planets, seen from the Earth, remained the same whether the sun revolved around the Earth or vice versa. But the temptation to consider the Earth as any other planet was too strong and Kepler adopted the Copernicus hypothesis.

Then came Galileo. The latter, a teacher at the University of Padua and persuaded of his success in astronomy, affirmed himself high and strong Copernican.

The Church then reacted by the decree of 1616 , which condemned two Copernican propositions:

a. The sun is the center of the world, and

b. The Earth is not the center of the world and moves.

Despite this condemnation, Galileo wrote "Il Dialogo" which will have him condemned in 1633, by the Holy Office.

The first proposition of Galileo: "The sun is the center of the world and it is absolutely deprived of local movement", was also condemned by the Tribunal of the Holy Office in the following terms: "it is absurd and false in philosophy and formally heretical as contrary to the Holy Scriptures".

The second proposition: "The earth is not the center of the world and it moves not only in space but also diurnal movement on itself", was also considered "absurd and false in philosophy and (to) be theologically considered at least erroneous in faith ".

Galileo did not demonstrate that the sun was the center of the world. But the condemnation of the second proposition results from the influence of Aristotle within the Church.

This condemnation created reactions among philosophers.

To start with, the "Discourse on the Method" of Descartes (1637), considered that a complete mathematization of science, made science no longer rest on facts, but first on clear and distinct ideas, making reason the natural light, hence the "philosophy of enlightenment". This will not be without consequences on the other scientific disciplines, as we will see in geology, because rationalism reverses scientific reasoning, when, instead of relying on the observed and experienced facts from which hypotheses are induced, it privileges the a priori of reason as its foundation: principles, postulates, laws ..., and retains only the facts, sometimes misinterpreted, which comfort them. Thus, from Descartes to Hegel, the rationalisms developed, first against the Church, as Voltaire is the example, then against the monarchy, in 
France, where the Revolution generated the terror of Robespierre and the wars of Napoleon.

\section{Astronomy}

In 1958, the journal of the Ecole Polytechnique published an article by Maurice Allais, X31, Nobel Prize in Economics, who was interested in gravimetry by making pendular experiments, showing that, besides the FOUCAULT effect, the result of the diurnal rotation of the Earth, an azimuthal displacement was manifested. In addition, pendulous experiments initiated by Maurice ALLAIS during solar eclipses also revealed an azimuthal displacement of the pendulum. This, according to Maurice ALLAIS questioned the law of Newton, which led me to read the book of Newton, the "Principia Mathematica", published in 1687, where he expressed his laws.

In his work, he writes in his PROPOSITION VI, page 82: "That the fall of the grave, takes place in equal times while ignoring, at least, the delay caused by a very weak existence of the air, others than me have observed it for a long time". Newton then formulates new laws of motion.

Law 1: "All bodies persevere in their state of rest or of uniform movement, unless imprinted forces compel them to change". This law does not define the effect of gravitation.

Law 2: "The change of movement is proportional to the imprinted motive force, and is affected along the line in which this force is imprinted". The imprinted force is the weight, therefore proportional to the mass of each body, which does not correspond to the gravitation which imprints the fall of the grave in equal times.

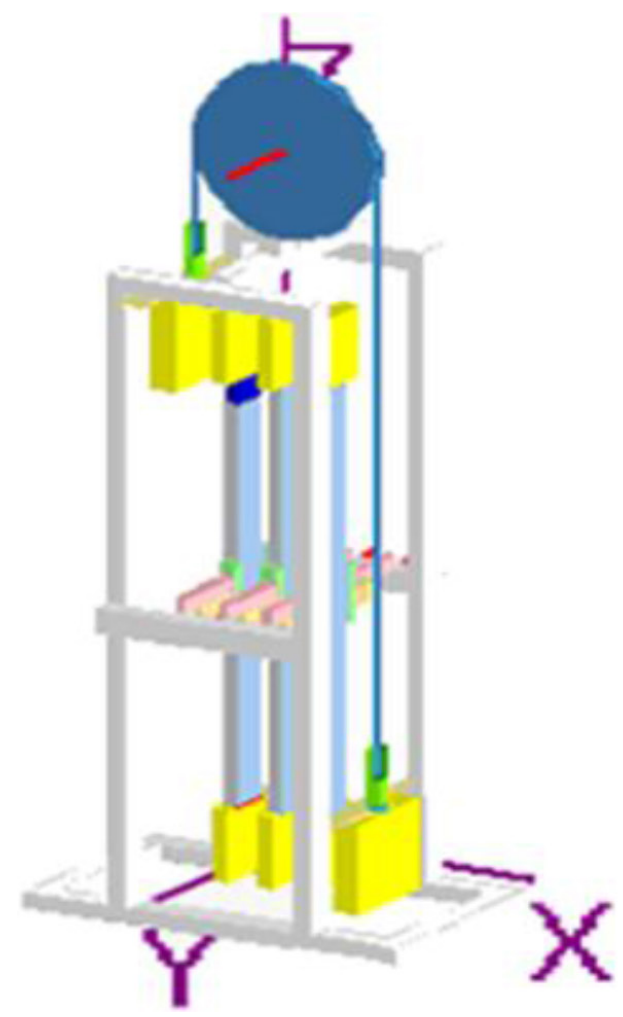

Law 3: "The reaction is always contrary and equal to the action". Newton refers to other actions than gravitation, such as pressure or pull or shock on another body, and a horse pulling a stone attached, forgetting the case where the galloping horse, drives the stone, in which case the action of the horse is not equal to the reaction of the stone. These examples are all alien to the action of gravitation, of which the only law, recalled by Newton, is expressed in Proposition VI.

This puts into question the reciprocal attraction between two orbital stars $\mathrm{F}=\mathrm{F}^{`}=\mathrm{G}$

\section{$\mathrm{M} \mathrm{M}^{\prime}$}

$D^{2}$, where $F$ and $F^{\prime}$ express the mutual force of attraction, $M$ and $\mathrm{M}^{\prime}$ the masses of the bodies, $\mathrm{D}$ their distance, and $\mathrm{G}$ a constant. It is this reciprocity that has determined the calculation of the masses of the sun and the planets. In February 2014, the Royal Society brought together the main specialists measuring the G constant, on the theme: "The Newtonian constant of gravitation, a constant too difficult to measure", whose differences ranging from 6,672 to 6,676 . Is the constant, constant or not?

Let us add that at present, we know the effect of gravitation, but not the cause.

I therefore concluded an experimental gravitation contract with the Royal Observatory of Belgium, directed by Professor Michel van Ruymbeke [1] .

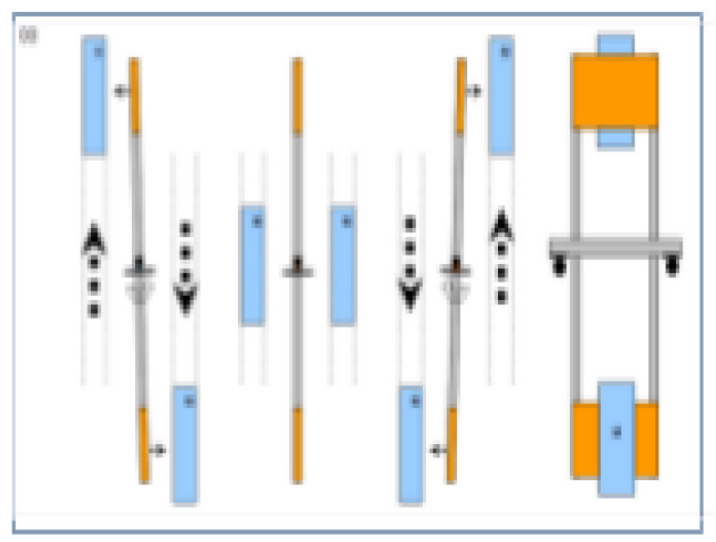


The experiment consists in subjecting a vertical pendulum to the attraction of masses of the same volume, copper, aluminum, Plexiglas, nonmagnetic, and magnetic iron, mounted on a pulley. The result of the measurements shows that the attraction does not depend on the material used, magnetic or not, but only on the attractive mass. The second experiment will consist in checking the Earth's screen effect on solar attraction, measured by a pendulum, exposed or not to this attraction, according to the terrestrial rotation.

The other question concerns the interferometric experiments of Michelson (in 1881), Michelson and Morley (1887) and Morley-Miller (1902-1905) which did not evidence the speed of the Earth of $30 \mathrm{~km} / \mathrm{s}$ in the ether which was supposed to be immobile. These results plunged the physicists into an enormous embarrassment, and led Einstein to state the two postulates of his special relativity in 1905. Such a theory was by no means necessary. The failure of these experiments implied that of the immobile ether hypothesis. It had to be admitted that the speed of the ether on the earth's surface was, according to the interferometric experiments carried out to date, either null according to most of them, or weak according to Miller, as had justified Maurice Allais. Let's come to the Big Bang. This is based on the fact that the spectrum of light emitted by distant galaxies has a red shift. Based on the Doppler effect, which is the apparent frequency variation of the sound of a whistle of a train that crosses the observer (higher as it gets closer, lower when it moves away), and in applying it to light, it has been shown that galaxies recede. In 1928, Hubble will formulate his law $\mathrm{v}=\mathrm{Hr}$, where $\mathrm{v}$ is the speed of recession of the galaxy, $\mathrm{r}$ its distance, $\mathrm{H}$ a constant. Georges Lemaitre then made the thesis of a recess of galaxies from a single explosion, called the Big Bang. This is not demonstrated with facts. But we can, with facts, explain the phenomenon differently. The sun is yellow at the zenith, red-orange at bedtime. The color is a function of the path in the atmospheric air of the rays that are observed. The rays emitted by distant galaxies cross the gaseous atmosphere of many galaxies, resulting in a red shift.

\section{Geology}

Let us come to the other great discipline, whose a priori has had as many implications: Geology.

Its founder, Nicolas Stenon, who intended to "walk in a very exact and orderly way, according to the method of Descartes", defines the foundations in 1667 in his book "Canis Calchariae", interpreting the superposition of strata as a succession of sedimentary deposits [2], lacked of underwater observations. He deduced in 1669, in "Prodromus", the principles of stratigraphy, namely, superposition, continuity and original horizontality of strata, which are at the base of the relative scale of geological time. Charles Lyell defines from it absolute chronologies. In 1828 he traversed the Auvergne, and became interested in laminated deposits of fresh water. Noticing foliated strata of less than a millimeter that he attributed to an annual deposit, he realized that the whole (230 meters), took hundreds of thousands of years to form. In his "Principles of Geology" (1832), he noted that the fauna was renewed by $5 \%$ during the "ice age". Assuming a constant rate of renewal (uniformitarian hypothesis), it will take twenty times longer for a "revolution" in wildlife to occur. But Lyell has had four revolutions since the end of the secondary era, and eight more for earlier times since the beginning of the primary era. And as his contemporary James Croll estimated, for astronomical reasons, that the ice ages lasted a million years, Lyell sets the primary base at 240 million years. Duration increased to 560 million years ago by radiometric dating in the $20^{\text {th }}$ century.

It was this succession of species during a very long time that led Darwin to express, in 1859, his theory in his work "The Origin of Species". It is that of the natural selection of species by the struggle for life, inducing their evolution over time. Two years later, Marx wrote to Lassalle: "Very significant is the work of Darwin, which suits me as a foundation in the natural sciences of the class struggle in history". Engels on his side, in "Ludwig Feuerbach and the End of German Philosophy" acknowledged "Darwin's overall demonstration made for the first time that all the products of nature that now surround us, including men, are the product of a long process of development from a small number of unicellular germs originally, and that the latter are, in turn, from a protoplasm or albuminoid body made by chemical means". And he immediately deduced from Darwin's "discovery" a law of evolution of societies: "But what is true of nature and also recognized as a process of historical development, is also true of history of society in all its branches and all of the sciences that deal with human and divine things".

Scientific socialism thus derives from Darwin, as does National Socialism, which preached the supremacy of the Aryan race. Hence the Gulag, and the Shoah, which have claimed more than 60 million lives. As for the historical geology, based on the interpretation of Stenon, this one is not proved, because no one has witnessed stratification.

That is why I started an experimental program to study stratification in 1970. There exists in the sedimentary rocks, layers of slight thickness, millimetric, or "laminae", which are similar to the "foliated strata" observed by Lyell, mentioned earlier. I took a sample of "Fontainebleau sand", presenting these "laminae", weakly cemented. I broke the cement and obtained heterogranular sand, that is to say composed of particles of different sizes.

I dropped the sand into a glass tube, and saw the same lamination in the deposit similar to that of the sample, and this at whatever rate of sedimentation that I operated. As shown in the attached photos. I understood then that this phenomenon could result from sand being a powder whose mechanics is intermediate between that of liquids and solids. If, in a tube, three solid bodies are successively dropped, these bodies are arranged in the order of their succession. Whereas if three liquids of different densities, mercury, oil, water, are dropped, they will be superimposed in the order of decreasing densities, under the effect of gravity. Gravity could therefore be expected to cause repetitive granulation of the sand particles according to their size. Lamination is a mechanical phenomenon, not a chronological one. As a result, the thousands of "foliated strata" observed by Lyell do not correspond to hundreds of thousands of years (Figure1 and 2).

The report of my experiments was presented by Professor Georges Millot, Director of the Institute of Geology of Strasbourg, Dean of the University, member of the institute, then President of the Geological Society of France, at the Paris Academy of Sciences, which published it in its reports in 1986 [3]. Thereafter, the Professor admitted me to the Geological Society of France, as a sedimentologist. I then did the same 
experiment with a laminate sample containing fossils. The result was the same, and was also published by the Academy of Sciences in 1988, presented by Georges Millot [4].

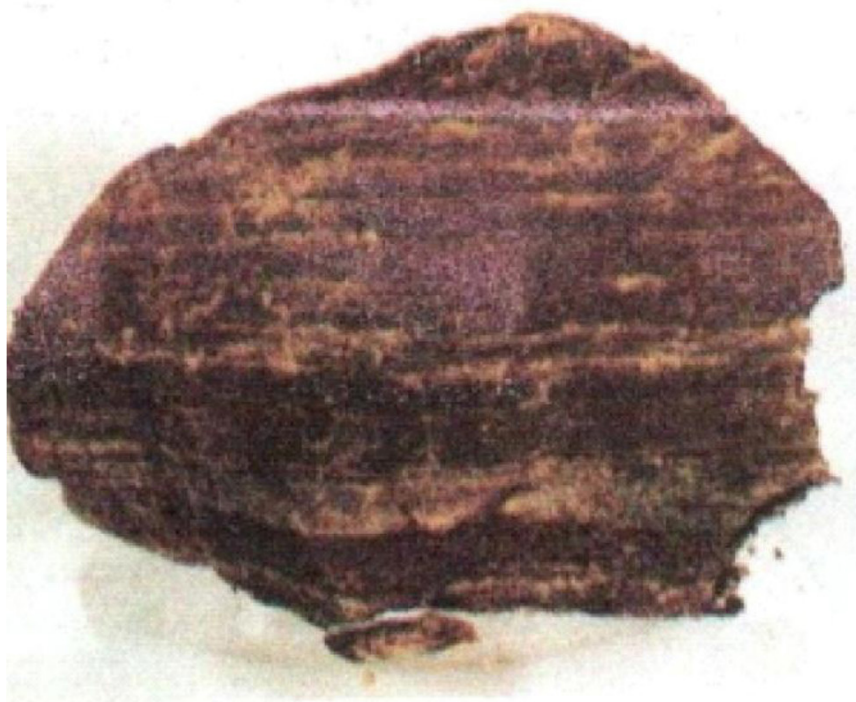

Figure 1. Diatomite sample

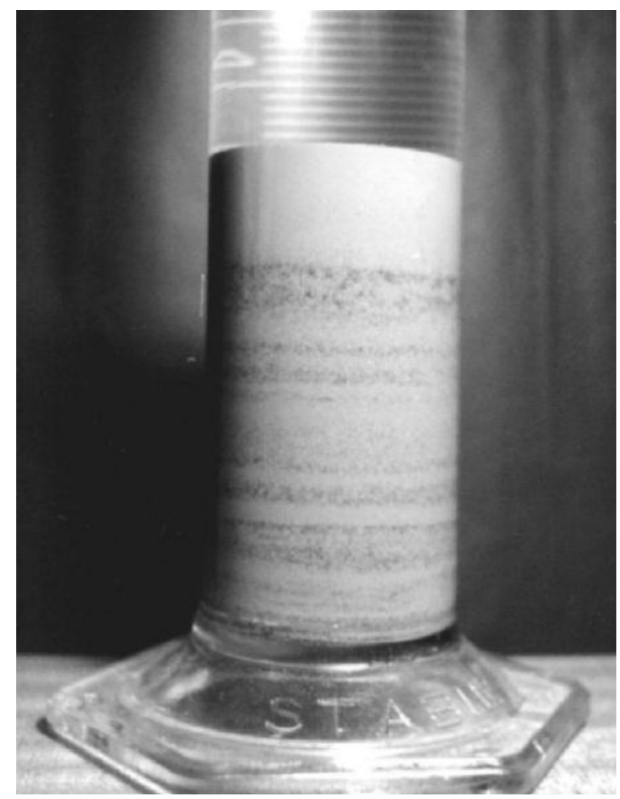

Figure 2. Lamination resulting from dry run

\section{What about thick stratification?}

A report titled "Jewel Creek Flood" [5], published in the US, authored by American geologist Edwin Mac Kee, reported stratified deposits on the banks of "Bijou Creek" resulting from a flood of the river from the Rocky Mountains, due to snowmelt and increased by heavy rains. This phenomenon did not last more than 48 hours. Given the continuity of the flow, there was no question of supposing that a first stratum had become rock, before the second covered it, as the principle of superposition had affirmed. The strata were about $10 \mathrm{~cm}$ thick (see Figure 3a,b).

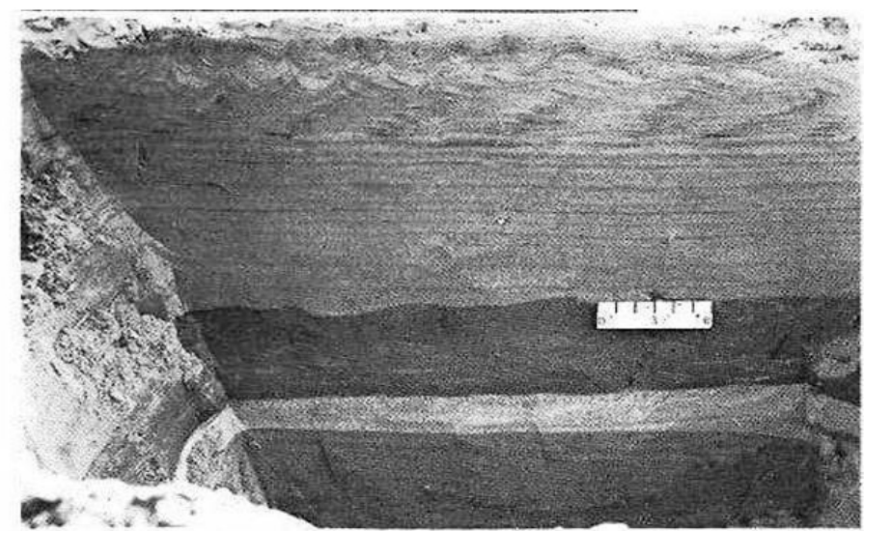

b

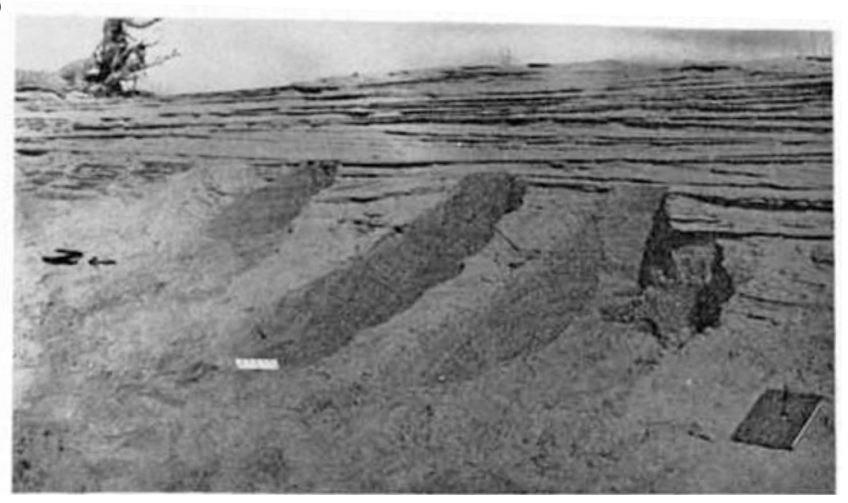

Figure 3. Sedimentary structures of the East Bijou stream flood in 1965

a) alternating strata of sand and muddy sand - b) stratification of deposits

To explain the phenomenon, it must be taken into account that the river in flood reached a velocity of $7 \mathrm{~m} / \mathrm{s}$ in turbulent regime, and where, in each area of the river, the speed of the current varies alternately from the surface to the bottom. However, sedimentologists such as Hjulstrom and Lichstvan-Lebedev [6], have experimentally determined the critical rates of deposition of particles of different sizes. In a flood situation, the sediment transport capacity of the current is very high, and the speed variation in each area, when it becomes critical, causes the sedimentation of quantities of particles of different sizes, so that the gradation observed in calm water becomes thick "layers" of several centimeters. Similarly, in 2008, the Journal Sedimentology published an article on the 2004 tsunami in Southeast Asia, which presents photos of the tsunami's deposit in a few hours, showing strata of $20 \mathrm{~cm}$ superimposed.

It seemed to me necessary to study stratification in the laboratory. An experimental report from a group of American sedimentologists operating at the University of Colorado Hydraulic Laboratory, of a flowing canal, showed the presence of strata in the deposit. I therefore proposed to study the causes, and went there for this occasion. I signed a contract with the University, and it was the group's assistant, Pierre Yves Julien, a young Canadian hydraulist and sedimentologist, who carried out the experiences of the contract. In a canal, the water mixed with sand, whose large particles are black and the small white, is pumped in a circulating circuit. The color contrast of the particles 
allows the observation of the stratification in the sedimentary deposit which develops both laterally, in the direction of the current, and vertically as it thickens. The deposit is laminated and stratified. A lateral section of the deposit shows a superposition of layers several centimeters thick, as shown in the photos below. The report of this experiment was published in 1993 in the Bulletin of the Geological Society of France [7] (Figure 4-6).

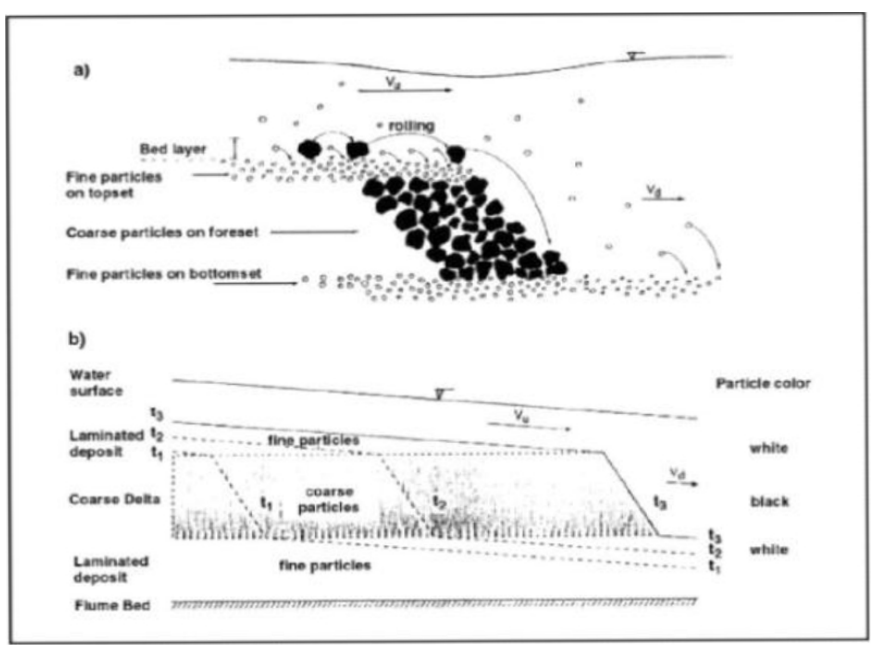

Figure 4. Formation of granulated layers

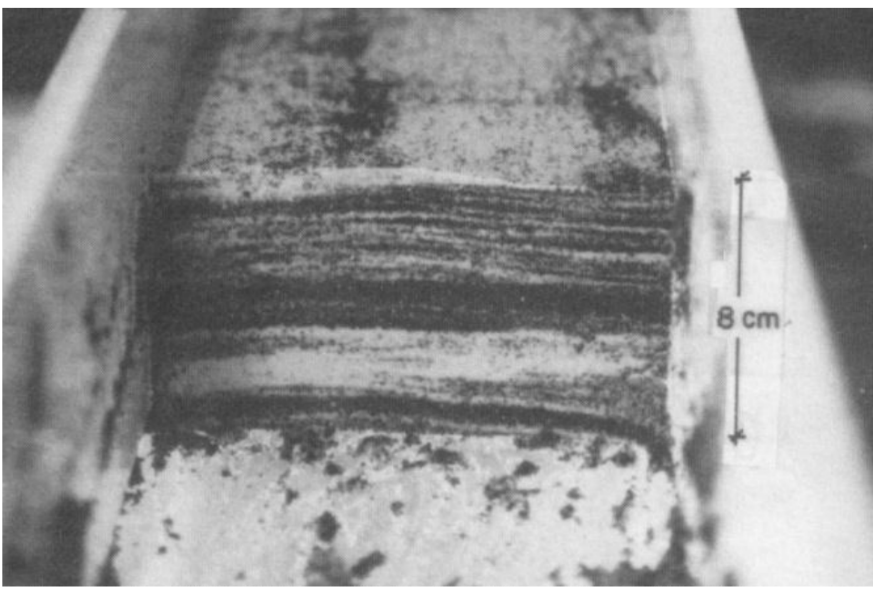

Figure 5. Transversesection of the deposit

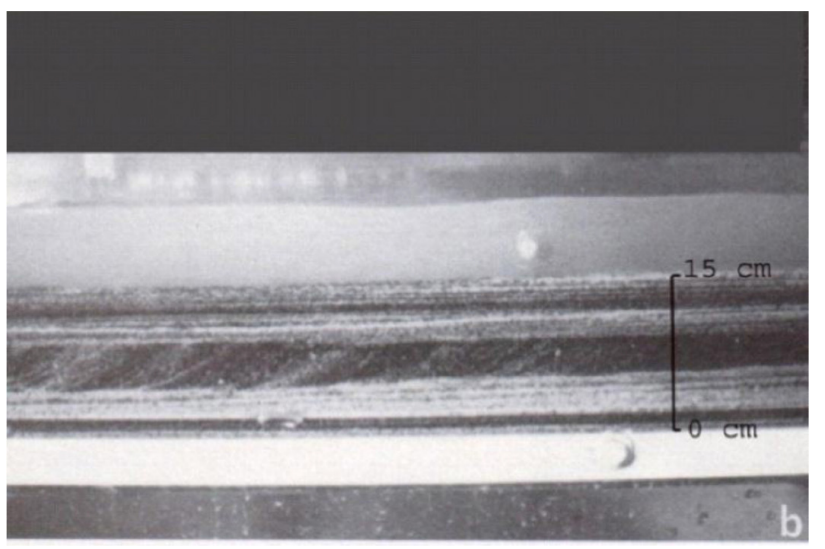

Figure 6. Longitudinal view of the deposit
To develop a chronology resulting from sedimentation, it is necessary to refer, as cause, to the marine movements, ascending or descending, which deposit stratified sets called "sequences".

The book "Base of Sédimentologie" of the Association of French Sedimentologists, says: "Sedimentology studies how are formed the solid envelopes of the Earth and planets, subject to the action of water, wind and gravity ". Stenon's a priori are no longer the basis. In the early 2000s, the time came for me to apply the lessons learned from my experiences, complemented by other sources on the ground. Being 75 years old, there was no way I could participate. But I was lucky when I went to Moscow at that time to meet a young geologist and sedimentologist, Alexandre Lalomov, who took a great interest in my published works. Thanks to him, I was able to publish in 2002, under the title "Analysis of the main principles of stratigraphy on the basis of experimental data", in "Lithology and mineral resources", journal of the Academy of Sciences and the Institute of Geology of Russia, a report of our work conducted in the USA [8].

In 2004, the same magazine published my, "Sedimentological Interpretation of the Tonto Group", explaining that the facies of a geological series are both superimposed and juxtaposed on the deposit area, which is due to the current Sediment supply [9]. My work was also published in China [10].

Alexander Lalomov determined, in several regions of Russia, the hydraulic and sedimentary genesis of rock formations in Crimea, the Urals and the Saint Petersburg region [11].The most decisive of his works was the determination of the sedimentation time of rock formations, such as the Cambrian-Ordovician sandstone formations of the Saint Petersburg region. Sedimentary mechanics assess the sediment transport capacity of currents from critical paleo current velocities, as a function of particle size. The quotient of the volume of the rock formation studied by this capacity, per unit of time and volume, indicates the corresponding sedimentation times. This method is applied by many sedimentologists, names of which I would quote HA Einstein. The time determined by this method, applied to the aforementioned Cambrian-Ordovician sandstones, represents $\mathbf{0 . 0 5 \%}$ of the time of the geological scale. The report of this study was published in 2011 in "Lithology and Mineral Resources", journal of the Academy of Sciences and the Institute of Geology of Russia [12].

The sedimentary chronology is no longer based on stratification. This is why the stratigraphic chronology is belied by the aforementioned experimentation. In addition, sedimentary rocks are not radiologically dated, only igneous rocks can be.

Golovkinskii (Kazan-1868), on rocks, and Walther (1894), on marine sediments, established that: "Only facies and facies areas juxtaposed on the surface, could be superimposed originally" [13]. As it was shown, in my 2002 publication, facies, both superimposed and juxtaposed, constitute a sequence resulting from a transgression or marine regression. A succession of sequences included between a transgression followed by a final regression is a "series". The data of the sequential stratigraphy and the experiments mentioned above, show that a series corresponds to a period. Therefore, the sequence should be considered as the base reference of the relative chronology, instead of the stage. 
Today, sedimentologists, based on the results of their underwater observations and their laboratory experiments, have established relationships between hydraulic conditions, depth and particle size. This makes it possible to determine the critical transport speeds below which a particle of a given size is sedimented. The St. Petersburg Hydraulic Institute has carried out at my request an experimental program of erosion of sedimentary rocks by strong currents $(\mathrm{v}<27$ $\mathrm{m} / \mathrm{s}$ ) to complete these relations [14]. Others will have to follow. For information, all our publications and experiences are on my website www.sedimentology.fr. By clicking on "Video", you can see my experiences.

As a result, the geological time scale must no longer be based on the superposition of strata. It must be based previously on the sedimentary genesis, involving on the one hand gravitation, for the formation of the lamination, and on the other hand the turbulent flow velocity, for the formation of superimposed and juxtaposed stratified facies, constituting the sequences. As for absolute time, the foliated strata that Lyell observed, and taken for annual deposits, are mainly laminae which, as I have shown experimentally, do not characterize any absolutetime. The same is true of his 240 million-year chronology, based on the biological "revolutions" that Professor Gohau has described as an "unproven, uniformitarian hypothesis". Professor Gohau in his book "A History of Geology" [15] said, "What measures the time, these are the times of sedimentation and not those of orogens and "biological revolutions". I add that the radiometric dating of rocks is questionable. As evidence, the potassium / argon dating of rocks, resulting from volcanic eruptions of known historical date, sometimes indicate millions of years. This results from an excess of argon largely from the lava that gave rise to the rock [16]. Christian Marchal, of ONERA, polytechnician also, published in 1996 in the "Bulletin of the Museum of Natural History of Paris" (completed by an erratum published in "Geodiversitas" - 1997), a study entitled "A probable cause of the large displacements of the terrestrial poles " [17], showing that the uplift of a large mountain range like the Himalayas modifies by several million the moments of inertia of the Earth, which is enough to move the position of stable equilibrium of the poles by tens of degrees. This study indicates that these pole displacements, combined with the rotation of the Earth, result in large transgressions and regressions of the oceans, their amplitude being much greater than the variations of the level of the oceans due to the melting of the glaciers consecutive to cyclical variations of orbital parameters of the Earth. This may explain, in addition to the paleo-hydraulic analysis data, the existence of diluvian conditions in the geological past, generated by the orogeny of mountain ranges, in addition to those attributed to the fall of meteorites. As it is said in the Eocene Bulletin, the North Pole, before the Himalayan orogeny, was at the mouth of the Siberian Yenisei River at 72 degrees north latitude. After the orogenesis, he was in a position close to what it is today, after a shift of 18 degrees. The direction of the transgressions and regressions following each of the 19 orogeneses occurring since the beginning of the Primary era, corresponds to the succession of the resulting sequence facies, such as sandstone, clay, limestone. An example is the Tonto Group in the Cambrian. It proceeds from the Cadomian orogeny, at the beginning of the Cambrian, and results from a transgression from the Pacific
Ocean to New Mexico. Other directions may be determined by other orogeneses that occurred elsewhere on Earth.

Contemporary marine fauna varies with depth, latitude and longitude, and such diversification exists in the geological timescale. The apparent change of fossilized marine organisms from one series to another following an orogenesis may result from different faunas transported by currents from different places resulting from successive orogenesis. What has been attributed to a biological change may be ecological in nature, explained by fauna from different orogeneses, taking into account the short time of sedimentation. It should be added that dating by radiocarbon ( $\mathrm{C} 14)$ is done nowadays on the collagen of fossil dinosaur bones, which reduces their calculated age from 65 million years to less than 40,000 years. But this C14 dating is based on the assumption that the $\mathrm{C} 14$ concentration of the atmosphere remained constant over time, which cannot be verified. Overall, the radiometric dates are not conclusive. In conclusion of the geological chapter, a relation can be established between cause and effect. Orogeny, that is, rising mountains, which is contingent on volcanic eruptions [18], is the cause of displacements of the axis of rotation of the poles, which causes marine series and creates deposits, thus sedimentary rocks. The duration of these deposits being much shorter than the time indicated by the geological timescale leads to its necessary revision. I expressed this causal relationship in "Towards a refoundation of historical geology" [19], published in "Georesources", Journal of the Kazan University (12/2012), and in "Orogenesis, cause of sedimentary formations" [20], published in "Open Journal of Geology" at the International Conference of Geology and Geophysics held in Beijing (06/2013) [21]. I presented it at the Kazan Geology Conference in October 2014.

In his report, "Orogenesis of the Tertiary Age of the Ural Mountain System", Alexandre Lalomov draws the following conclusions:

Based on the geomorphology and velocities generated by current surface movements, the time required for the uplift of the Ural Mountain system is much less ( 0.5 to $0.7 \%$ ) than the corresponding time interval of the stratigraphic timescale.

Based on the sediment lithology and the geomorphology of the Ural valleys, the time required for the erosion of the valleys of most Ural rivers is much less ( 0.02 to $0.7 \%)$ than the corresponding time interval of the stratigraphic timescale.

The distribution of fossils in the Ural Orogeny deposits can be explained on the basis of ecological and facial zonings of the preogenic environment.

The report of "Reconstruction of Paleohydraulic conditions of deposition of the upper permian strata of the Kazan region" of A. Lalomov, G. Berthault, VG Izotov, LM Sitdikova, MA Tugarova was published in "Georesources" in 2017[22] and presented by Lalomov and myself on November 7, 2017 at the Kazan Geology Institute.

\section{Conclusion}

The fatal consequences of the a priori in natural sciences invites to base these on the observed and experienced facts, eliminating the a priori and errors of reasoning, which should be the subject of research 
by specialists of artificial intelligence. The history of the last centuries shows us well this sequence. Copernicus and Galileo affirmed, but without proof, that the sun was the center of the world. Had they merely spoken hypothetically, what Cardinal Bellarmin had asked Galileo to do, they would not have been condemned by the Holy Office, which, therefore, would not have denied the probable mobility of the Earth. There would have been no reaction against the Church. Similarly Descartes, if he had attached himself to the facts, he would not have based his judgments on the only clear and distinct ideas, persuasive ideas that led Stenon to his a priori, and Newton to his inexact laws set before the empirical evidence. Descartes thus engendered the philosophy of enlightenment, which, led the notoriously antireligious Voltaire to the revolution of 1789 and the fall of the monarchy of the Bourbons, replaced by Napoleon I and later Napoleon III, who unleashed wars. Objectively, these events should not have taken place. And without a historical geology based on an inexact a priori, Darwin would not have been led to write "The origin of species", postulating this struggle for life between species which inspired Marx and Engels to advocate for the class struggle. So Stalin might have remained a seminarian and Hitler, a painter, which would have saved us the Second World War. Their a priori having been revealed, the previous incidences collapse. We cannot change history. But by becoming once again objective, we should be able to make history return to the path of Truth, from a scientific, political, metaphysical, moral and spiritual point of view. Man, having no proof of an evolutionary cause of the universe, must, as did ancient civilizations, ask himself the question : "Who created the universe?". For believers, there is a spiritual response expressed by the Bible whose chronology has been challenged by the millions of years attributed to living species, including Man. Having challenged the foundations and chronology of historical geology, believers, freed from this geological challenge, can once again adhere to the credibility of the Bible, be it Jews, Christians or Muslims.

\section{References}

1. van Ruymbeke M (1979) A horizontal pendulum with zero method makes it possible to measure the constant of the universal gravitation G. Thesis Annex phd UCL.

2. Stenon N, Stensen N (1667) Canis Carchariae Dissectum Caput, KIU Aus., lat. u. engl. The earliest geological treatise.

3. BG Sedimentology (1986) Experiments on Lamination of Sediments, Resulting from a Periodic Graded-Bedding Subsequent to Deposit. report of the Academy of Sciences 303

4. Berthault G (1988) Sedimentation of a Heterogranular Mixture. Experimental Lamination in Still and Running Water. report of the Academy of Sciences 306: $717-724$.

5. McKee ED, Crosby EJ, Berryhill HL Jr (1967) Flood Deposits, Bijou Creek, Colorado, June 1965. Journal of Sedimentary Petrology 37: 829-851.

6. Lischtvan-Lebediev (1959) Gidrologia i gidraulika $v$ mostovom doroshnom. Straitielvie. Leningrad.

7. Pierre Y Julien, Yongqiang Lan, Guy Berthault (1993) Experiments on Stratification of Heterogeneous Sand Mixtures. Bulliten Of The Geological Society Of France 164: 649-660.

8. Berthault G (2002) Analysis of Main Principles of Stratigraphy. Lithology and Mineral Resources 37: 509-515.

9. Berthault $\mathrm{G}$ (2004) Sedimentological Interpretation of the Tonto Group Stratigraphy, Grand Canyon Colorado River. Lithology and Mineral Resources 39: 504-508.

10. Berthault G (2002) Geological Dating Principles Questioned Paleohydraulics a New Approach. Journal of Geodesy and Geodynamics 22: 19-26.

11. Lalomov A (2007) Reconstruction of Paleohydrodynamic Conditions during the Formation of Upper Jurassic Conglomerates of the Crimean Peninsula. Lithology and Mineral Resources 42: 268-280.
12. Berthault G, Lalomov A, Tugarova MA(2011) Reconstruction of Paleolithodynamic Formation Conditions of Cambrian-Ordovician Sandstones in the Northwestern Russian Platform. Lithology and Mineral Resources 46: 60-70.

13. Middleton GV (1973) Johannes Walther's law of the correlation of facies. Geological Society of America 84: 979-988.

14. Berthault G, Veksler AL, Donenberg VM, Lalomov A (2010) Research on Erosion of Consolidated and Semi-Consolidated Soils by High Speed Water Flow. Izvestia VMG 257: 10-22.

15. Gohau G (1990) A history of geology. Paris Seuil Pg No: 277.

16. Funkhauser JC, Naughton JJ (1968) Radiogenic helium and argon in ultramafic inclusions from Hawai. Journal Geological Research 73: 4601-4607.

17. Marchal C (1997) Earth's Polar Displacements of Large Amplitude. A Possible Mechanism. Bulletin of the National Museum of Natural History 19.

18. Rampino MR, Prokoph A (2013) Are Mantle Plumes Periodic?. EOS Transactions American Geophysical Union 94: 113-120.

19. Berthault G (2012) Towards a Refoundation of Historical Geology. Georesources Pg No: 4-36.

20. Berthault G (2013) Orogenesis, cause of sedimentary formations. Open Journal of Geology 3: 22-24.

21. Dilly R, Berthault G, Lalomov A (2015) Orogenesis, cause of sedimentary formations, $8^{\text {ème }}$ conférence lithologique "Evolution des processus sédimentaires dans l'histoire de la terre", Académie des Sciences et Université gouvernementale du pétrole et du gaz, Moscow.

22. Lalomov A, Berthault G, Izotov VG, Sitdikova LM, Tugarova MA (2017) Reconstruction of Paleohydraulic conditions of deposition of the upper permian strata of the Kazan region. 19: 101-110.

Citation:

Guy Berthault (2019) The Fatal Consequences of a Priori in the Natural Sciences, to be Replaced by Facts. Geol Earth Mar Sci Volume 1(1): 1-7. 